\title{
PARAPHRASING CHALLENGES FACED BY MALAYSIAN ESL STUDENTS
}

\author{
Ida Fatimawati Adi Badiozaman \\ Faculty of Language and Communication \\ Swinburne University of Technology, Sarawak Campus \\ ifaBadiozaman@swinburne.edu.my
}

\begin{abstract}
This study examined the challenges faced by Malaysian second language (L2) learners when paraphrasing an academic text. Drawing on interviews with two diploma students from two business majors, I explored the types of challenges they faced when attempting paraphrasing tasks. The findings revealed that the students faced multiple challenges that ranged from text comprehension, poor L2 proficiency to referencing problems. In addition, there were significant differences between paraphrasing strategies adopted by a competent student and one with a lower proficiency level. Overall, the findings suggest that there is a need to utilise ContentBased Instruction to make the links between writing skills and learners' disciplines tangible and that pre-degree preparation needs to include extensive writing practice which would help students become familiar with academic writing demands. Preliminary results also show that there is a need for teachers to be aware that the design of the materials for English language teaching should be tailored to the purpose of university study and academic vocabulary.
\end{abstract}

Keywords: academic writing; paraphrasing, academic literacy, English as a second language

\section{Introduction}

The ability to write in a second language is contingent on multiple, complex and often dynamic factors. Yet, L2 learners in tertiary institutions are often evaluated based on their academic literacy; particularly academic writing skills. These evaluations may take the form of writing a literature review, integrating other's written ideas into one's own academic writing such as direct quotatiion, summarising, paraphrasing and synthesis essays. In various studies, students are depicted as using limited writing strategies (e.g., Abdullah et al., 2011, p. 102), with a tendency to plagiarise (Smith, Ghazali, \& Noor Minhad, 2007) and as being plagued with proficiency deficits in their writing outputs (Badiozaman, 2012).

L2 writers, who are still in the process of acquiring linguistic competence, will probably face difficulties when attempting to become competent in a rhetoricspecific area, such as academic writing. Anstrom et al. (2010) stated that academic English is the reason for the discrepancy between English language learners and English-proficient students. Similarly, Zhang and Mi (2010) identified language 
difficulties as one of the major obstacles for international students' academic endeavours. In the Malaysian tertiary setting, research has also revealed that $L 2$ writers learning academic writing in English not only have to master academic English, but also gain advanced writing skills (Puteh, Rahamat, \& Karim, 2010).

Attempts to understand why Malaysian students still "struggle to comprehend advanced level reading texts in English ... lack reading skills and are not critical readers" (Shafie \& Nayan, 2011, p. 2) despite having learned English for 11 years, have revealed there are not only linguistic, but also pedagogical challenges affiliated with learning academic writing in L2. To illustrate, despite the claims of academic writing being explicit, an ongoing debate within the research of academic writing is that academic writing is rather tacit (Elton, 2010; Green, 2010) for native speakers. In particular, Lillis (2001) argued that the focus should be transferred from students' 'problematic' language to the institutional practices of teaching academic writing, whereby "the language of disciplines and the pedagogic practices in which these are embedded usually remains invisible" (p. 22).

Although considerable research has been devoted to investigating the challenges in L2 reading or writing (Leki, Cumming, \& Silva, 2008), little is known about the challenges faced by Malaysian L2 tertiary learners when they are required to integrate reading-writing skills. Aside from plagiarism-related studies (e.g., Abasi, Akbari, \& Graves, 2006; Smith et al., 2007; Wette, 2010; Yigitoglu, 2010) there has been relatively few research investigating the act of paraphrasing itself. In fact, there has been little research looking into the challenges that Malaysian learners face when engaging in a paraphrasing task. Thus, the study examined the processes and challenges faced by L2 learners in paraphrasing an academic text.

\section{Review of Literature}

In universities, students are required to take academic literacy classes where they are taught skills that would allow them to function effectively in an academic setting. The required preparatory papers may have different names but they have the similar objective of preparing learners with the necessary skills and knowledge required at diploma or degree level that enable them to function effectively within an academic environment. As such, academic literacy programs in tertiary level would require students to have such as summary writing, paraphrasing and synthesising skills, to name a few. As students at tertiary level are often required to integrate sources into their own work, Barks and Watts (2001) offer the "triadic model" of "paraphrase, summary, and quotation" (p. 252) as techniques of integrating sources into their written work. This is contingent on the fact that it requires high levels of language processing ability (Berman \& Cheng, 2010) and "involves the orchestration of multiple language skills" (Wolfersberger, 2013, p. 50).

Paraphrasing in particular, is a testament to this complexity. Unlike summaries which focus on restating only main ideas, paraphrasing is typically defined as the act of restating information and ideas expressed by someone and presenting it in a new form. Paraphrasing is achieved by the use of synonyms, changing word forms or rearranging the sentence structure. Hirvela and Du (2013) adds that "in paraphrasing, the writer recasts individual sentences, creating 
combination of original language and grammatical structures for the source text with some new words and grammatical structures" (p.88). A sentence has to be restated in such a way that it is lexically and syntactically different, while remaining semantically equal (Pecorari, 2003). Paraphrasing requires ESL learners to be proficient in reading and writing strategies (Leki et al., 2008), and the English language (Yu, 2008). To elaborate, learners have to comprehend the text at both macro and micro levels (Sedhu, Lee, \& Choy, 2013). Only when comprehension is achieved, can learners proceed with the writing task. In addition to that, the source text also has to be acknowledged and integrated into the writing in the form of citations, quotations and referencing.

During a paraphrasing task, reading and writing become highly interdependent. A study by Johns and Mayes (1990) which investigated ESL university students' processes of summarising revealed that those with lower proficiency were at a significant disadvantage as they were unable to understand the passage and consequently resorted to copying or produced an inadequate paraphrase (i.e., changed the meaning of the original text). In fact, Gebril and Plakans (2013) have argued that for reading-to-write tasks, "a proficiency threshold must be crossed for students to be able to synthesise information appropriate from the source text in their writing" (p. 22). In fact, earlier studies have provided evidence that low proficiency learners are prone to replicate sentences from the original texts rather than paraphrasing (see Johns \& Mayes, 1990; Sun, 2012). Insufficient lexical knowledge may also account for such problems (Abasi \& Akbari, 2008; Bloch,2009; Pecorari, 2003). All these variables often result in what is called patchwriting.

Howard (1995) defines patchwriting, as "the borrowing of source texts and making surface-level changes by modifying parts of the texts, such as plugging in synonyms and changing the verb" (p. 797). As such, traditionally, this was strongly linked to plagiarism (Howard, 1995). Nonetheless, with greater understanding of the $\mathrm{L} 2$ writer, the discussion regarding patchwriting is fast becoming pedagogical. In literature, patchwriting, which consists of lifting phrases and words from the source texts and interspersing them in one's own writing without quotation marks and citations, is seen as a necessary learning strategy (Pecorari, 2003). This study adopts a similar perspective as the students in question are novice student writers of L2 who have minimal experience with academic writing conventions. Accordingly, patchwriting is recognized as a (paraphrasing) strategy. Further, as the focus is on exploring the challenges and processes of paraphrasing for these learners, this necessitates a "pedagogical rather than punitive response" (Pecorari, 2003, p. 320). Howard (1995) explains:

Patchwriting is not always a form of academic dishonesty; it is not always committed by immoral writers. Often it is a form of writing that learners employ when they are unfamiliar with the words and ideas about which they are writing. (p.799)

More recent literature on paraphrasing has revealed that patchwriting needs to be seen as a learning opportunity and there is a developmental dimension, particularly for ESL learners. Within this dimension, students undergo several series 
of learning curves. , It is expected that students would struggle at the beginning stages and they would gradually acclimatise to the demands of paraphrasing. Hirvela and Du (2013) maintains that "it is essential that teachers look at paraphrasing through that lens [learner trajectory], especially in helping them transition from knowledge telling to knowledge transforming" (p. 97). Shi's (2004) study revealed the prevalence of this phenomenon: "much L2 writing by university students is patchwriting, interwoven with sentences or phrases copied from original sources" (p. 173). That there often is acknowledgment of sources alongside the patchwriting paraphrase further highlights the unlikely possibility of deception, but rather these novice student writers have limited language ability or do not have full comprehension of the original source.

Generally, literature in this area has consistently shown that paraphrasing is a challenging task for L2 writers. As yet, there has been no research looking into the specific processes that Malaysian L2 learners incorporate both in the reading and writing stages of paraphrasing. To shed light on this, the key research questions for this study were formulated as follows:

(1) What are the processes involved when the two L2 writers engage in a paraphrasing task?

(2) What are the reported challenges faced by the two L2 learners when paraphrasing an academic text?

\section{Methodology}

\section{Research context and site}

The study took place in 2013 at a private university in Sarawak, Malaysia, where English is the medium of instruction. The diploma program in this university offers various English courses which are offered in tandem with their content papers. In these courses, learners are taught different types of academic conventions; the incorporation of multiple sources in their writing; the correct acknowledgment of these sources and engagement in academic criticism. Students would typically have to undertake one English paper per semester, in addition to their content paper.

\section{Participants}

The participants of this study were Malaysian learners, aged between 19 and 21, who come from national schools. These learners generally had English as a second language and might speak more than three languages. The participants had completed their primary and secondary level education and met the requirements to undertake the diploma programme at higher learning institutions. Both students in this study were in their final semester of their diploma program and thus, were taking the final English paper as part of the academic literacy course. This final English paper required them to write a research report which involved several paraphrasing and summarising tasks. These tasks ultimately led to an extended literature review of their chosen topic which formed one aspect of the overall research report. The two students the researcher focused on in this article, Farid and 
Helen (pseudonyms), were selected because they highlighted different issues faced when engaging with paraphrasing tasks.

Table 1.

Participants' background information

\begin{tabular}{lll}
\hline Name & Major & Year of study \\
\hline Helen & Business Management & Second Year Diploma \\
Farid & Business Marketing & Second Year Diploma \\
\hline
\end{tabular}

\section{Data Collection Method}

Interviews were chosen as the main instrument as they provide opportunities for learners to formulate and verbalise their views. Cohen and colleagues (2007) argue that "interviews enable participants to discuss their interpretations of the world in which they live and to express how they regard the situation from their own point of view" (p. 203) . Bogdan and Biklen (2007) maintain that "good interviews produce rich data filled with words that reveal the respondents' perspectives" (p. 104). This is particularly relevant to the study as each learner's engagement with the paraphrasing task (in L2) is unique.

In this study, semi-structured interviews which "have a set of key questions that are followed in a more open-ended manner" (Mutch, 2005, p. 126) were incorporated. Semi-structured interviews therefore allowed for flexibility while also providing "comparable data across subjects" (Bogdan \& Biklen, 2007, p. 104). These interviews allowed the researcher to gain a more in-depth understanding of how learners paraphrase, the challenges faced and also strategies adopted as part of the experience. The interview process was flexible (Janesick, 2000) in that more questions were added, refined and readjusted in the subsequent interviews due to emergent findings.

The interviews were conducted from $18^{\text {th }}$ to $29^{\text {th }}$ November 2013 , which was towards the end of the semester in a neutral and non-threatening location such as discussion rooms in the library and tutorial rooms in the university. The students were asked to paraphrase an extract from their course material and were interviewed subsequently regarding the processes and challenges faced when paraphrasing the academic text. The interviews were conducted in English and Bahasa Melayu, the native language of the research subjects and the researcher.

\section{Data Analysis}

The analysis of data from the semi-structured interviews involved several (not necessarily distinct) steps, namely, transcription, coding, analysis and interpretation (Bogdan \& Biklen, 2007). Data interpretation of the qualitative phase was carried out inductively. Literature indicates that this approach emphasises how meaning is to emerge from the data (Barbour, 2008). In fact, the strategy of inductive analysis "is to allow the important analysis dimensions to emerge from patterns found in the case under study without presupposing in advance what the dimensions will be" (Patton, 2002, p. 56). 
Findings emerged from the frequent and significant themes from the raw data, without the restraints of preconceived categories. The rich qualitative data were from the participant's own words/ language of how they understood their experiences of learning in the class. At the same time, the researcher acknowledged her position was subjective, due to her experience as an educator of ESL learners and her background knowledge on the Malaysian educational context. Thus, the analysis was influenced by the researcher's experience.

Students' paraphrases were analysed manually at the sentence level and were also submitted to SafeAssign, a software which identifies matches between students' submitted work and text that is available online (Blackboard Inc, 2010). This program allows for a more detailed analysis of the paraphrasing attempts done by the students as it can generate a similarity report in which comparison can be made between the work of the student and the original source.

As mentioned in the literature review, the definition of an acceptable paraphrase varies significantly. This study thus, adopted Keck's (2006) taxonomy as it offers a reliable method for classifying attempted paraphrases (see Table 2 below).

Table 2.

Taxonomy of paraphrase types

\begin{tabular}{ll}
\hline Paraphrase Types & Description of paraphrasing strategies \\
\hline Near Copy & $\begin{array}{l}\text { composed primarily of long copied strings taken } \\
\text { from the original excerpt. }\end{array}$ \\
Moderate Revision & borrowed entire clauses from the original \\
& - $\begin{array}{l}\text { made a number of lexical and grammatical } \\
\text { changes to the original } \\
\text { contained the writers' own elaborative phrase or } \\
\text { clause } \\
\text { made a number of clause-level changes as well as } \\
\text { changes to lexis }\end{array}$ \\
\hline
\end{tabular}

\section{Results}

In this section, the findings are presented through two individual cases to highlight the challenges in paraphrasing. Cross-case analyses occur after the case presentations.

\section{Farid}

Farid was a final-year diploma student in the Faculty of Business and Design. Farid was Malay and used mainly Malay language and a local dialect (Bahasa Sarawak) in everyday communication. Because of his low proficiency, Farid was required to take supplementary English papers along with other business classes in which he was enrolled. During the course of the interview, Farid requested to use English but code-switched at times, to express himself better. For the paraphrasing task, the report generated by SafeAssign was 30\% and classified as a "Near Copy" based on Keck's (2006) taxonomy. It is important to note that Farid's attempt at paraphrasing (see Table 3 ) reflected one of a summary as not only did it focus on 
only main ideas, but it was also significantly shorter in length than the original text. His paraphrasing attempt and his interview excerpts suggest misconceptions about paraphrasing.

\section{a) The novice $L 2$ writer and misconceptions about paraphrasing}

Farid recalled that his first encounter with the concept of paraphrasing was during orientation week of his first year as a university student. He reported that, “Back then, I didn't even know about paraphrasing. I just copy all the articles and put it in my assignment". It was only after the lecturer approached him about the matter that he realised what he did can be perceived as plagiarising. When further probed, Farid clarified that paraphrasing was very foreign to him as he was never taught the skill in secondary school.

Interestingly, although Farid has had at least four semesters worth of experience with paraphrasing, there were still some instances in which he had misconceived notions. To illustrate, when asked in the interview why he did not consider including quotes, Farid stated that, "I try my best to avoid quotations in my paraphrase ... I don't want ... if possible to have any original words in my work. I am worried about plagiarism". The emphasis on not copying someone's original words were repeated later in the interview as he maintained that "It's very important that your ideas and what you are writing is different from the original source ... yes ... it must be different".

The evidence of further misconceptions of paraphrasing is apparent in his paraphrasing attempt (see Table 3). Note that the sentence patterns were rearranged with language of original text still intact; it actually reflected one of a [poor] summary.

Table 3.

Farid's Paraphrasing Attempt

\begin{tabular}{|c|c|}
\hline Original text & Farid's attempt at Paraphrasing \\
\hline $\begin{array}{l}\text { Over the past two decades, the global } \\
\text { market of electrical and electronic } \\
\text { equipment (EEE) continues to grow } \\
\text { exponentially, while the lifespan of those } \\
\text { products becomes shorter and shorter. } \\
\text { Therefore, businesses as well as waste } \\
\text { management officials are facing a new } \\
\text { challenge, and e-Waste or waste } \\
\text { electrical and electronic equipment } \\
\text { (WEEE) is receiving considerable amount } \\
\text { of attention from policy makers. } \\
\text { Predictably, the number of electrical } \\
\text { devices will continue to increase on the } \\
\text { global scale. Consequently, the volume } \\
\text { of WEEE grows rapidly every year and is }\end{array}$ & $\begin{array}{l}\text { The global market of electrical and } \\
\text { electronic equipment (EEE) continues to } \\
\text { grow but the lifespan of the products } \\
\text { become shorter. Thus, this contributes } \\
\text { to e-waste that received attentions from } \\
\text { policy makers. Some components of } \\
\text { electronic products contain harmful } \\
\text { substances which can be a threat to the } \\
\text { environment and also human being. }\end{array}$ \\
\hline
\end{tabular}


also believed to be one of the most critical waste disposal issues of the twenty-first century. Compared to conventional municipal wastes, certain components of electronic products contain toxic substances, which can generate a threat to the environment as well as to human health.

*Note: Underlined words indicate similarity with original text

\section{b) Low L2 proficiency}

Farid reported that one of the biggest challenges for him in paraphrasing was to understand the given passage or extract. Paraphrasing then became a challenge as he was unable to comprehend and identify the main ideas of the reading passage. This was evidenced in the somewhat short paraphrase which he produced during the interview (see Farid's Paraphrase in Appendix B). Farid admitted "I had difficulty in deciding whether this needs to be in the paraphrase or not". Farid also disclosed that, "if the articles use jargons or words that I don't really know, I use a lot more from the articles, instead of my own words".

Due to his low L2 proficiency, Farid faced further challenges in terms of his limited vocabulary (e.g. "some words I don't know the meaning" or "I don't understand that word") and grammar. He further expanded his concern, "my vocab might be off ... it may not be suitable for this context ... or worse, I changed the meaning". In terms of grammar, Farid disclosed that there were two main issues that impeded his paraphrasing: (i) difficulty in changing word class (i.e. adjective to noun); and (ii) creating grammatically correct sentences. He explains, "I am worried that the new words don't fit ... and whether the sentence now is grammatically correct". Farid also emphasized that if he could do the paraphrase again at home, he would heavily consult a dictionary to guide him in his word selection. Evidently, Farid's low L2 proficiency contributed to the challenges he faced in paraphrasing. Farid summed it up succinctly when he explained, "English is very important. You cannot understand a passage if you don't have the language, and when you don't understand, how can you paraphrase?"

\section{c) Unfamiliarity with the topic and subject matter}

Another factor that influenced his paraphrasing was his unfamiliarity with the topic and subject matter. According to Farid, paraphrasing could be easy contingent on the articles or reading passage. He explains, "It actually depends on the articles. If the article is about an unfamiliar topic, use jargons or words that I don't really know, paraphrasing becomes harder". As revealed by his attempted paraphrase (see Table 3), Farid struggled with the topic of electronic waste (e-waste) and thus failed to paraphrase several main ideas of the passage. The analysis also revealed that the meaning of the paraphrase was altered. It is likely Farid's attempt at paraphrasing was a result of his lack of background knowledge of the topic. He 
explains, "A difficult passage like health related topic, science ... some are unknown to me. That makes it difficult. Changing the sentences will be harder".

Farid later added that utilising sources from his business papers in the English classes would actually be beneficial in helping him improve his paraphrasing skills because "then I need to focus only on the changing of words and sentences ... not worry so much about understanding new topics". Farid also relayed that "in my English classes in diploma, sometimes the materials cover topics that my classmates and I know nothing about. So that makes it very hard for us". Although Farid did not elaborate on what he meant as "hard", it is likely that his unfamiliarity with the subject matter of e-waste, and an amalgamation of the two aforementioned factors have contributed to his inadequate paraphrase.

\section{d) Processes of paraphrasing}

It is interesting to note that Farid spent the longest time (25 minutes) in Step 1 (see Table 4). He stated that he read the extract multiple times in order to understand it fully. The second step, which was drafting the paraphrase, took second longest as Farid had difficulty in deciding which parts were to be included in the paraphrase. Nonetheless, as indicated in the text analysis, there were several main ideas that were omitted which might have altered the meaning of the original text. Once he had decided on the parts to retained, he then proceeded to draft the passage. When paraphrasing, Farid utilised a very interesting strategy to construct new sentences. When asked how this strategy ensures that the sentence is dissimilar from the original, he explains:

... for example....by not inserting 'over the past few decades' and just starting the sentence with the main idea, 'the global market' ... some words I omit and I'll combine two points together. So that makes the word arrangement look different from the original.

Based on the above example, the process above can be described as deletions (Howard, 1995) whereby one to four words from the original source are eliminated. Additionally, Farid also included what Howard (ibid) describes as reversals which entail reversing the sentence structure or word structure. Because of his weak grammar Farid explains, "so what I do, I combine sentences, like the one at the back, goes to the front." He further justifies this paraphrasing process to compensate his weakness in grammar, "I lack [I am weak] in changing nouns to adjective and verb to adverbs. That's hard. I don't want the meaning to change".

In the text analysis, it also became evident that synonyms were substituted and interestingly for his case, the synonyms appeared to consist of mainly transitional words (i.e. but, also, thus). Farid explained that in addition to flow, he felt confident in using them. He stated, "Transitions are easier to change as synonyms ... and are easier to use". Farid also did not attempt to change the order of sentences in the final paraphrase. It is important to note that there were no citations in the paraphrase and no final checks were done to compare the finished product and the original text. 
Table 4.

Processes of paraphrasing

\begin{tabular}{|c|c|c|}
\hline Step & Action & Purpose \\
\hline 1 & $\begin{array}{l}\text { Reading the passage } \\
\text { Underlining main ideas } \\
\text { Circling words that can be replaced with a } \\
\text { synonym }\end{array}$ & $\begin{array}{l}\text { To understand the passage } \\
\text { (this is done many times) }\end{array}$ \\
\hline 2 & $\begin{array}{l}\text { Drafting the paraphrase } \\
\text { Combining phrases from different sentence } \\
\text { Omitting words that are deemed to be not } \\
\text { important } \\
\text { Adding synonyms }\end{array}$ & $\begin{array}{l}\text { To make allowance } \\
\text { wherever a change can be } \\
\text { made }\end{array}$ \\
\hline 3 & Comparing draft with the original & To make necessary changes \\
\hline 4 & Adding transitions & To ensure there is flow \\
\hline 5 & Final paraphrase & \\
\hline
\end{tabular}

It became apparent that the steps taken in order to paraphrase were very much shaped by his low L2 proficiency. Lifting exact phrases or word strings (Howard, 1995) from the original source and the omission of very important main ideas (i.e. "grow exponentially", "the number of electrical devices will continue to increase on the global scale" and "the volume of WEEE grows rapidly every year") indicate that the issues lie in not only the writing stage, but also in his reading skills and low English proficiency level. This was evidenced in his paraphrasing attempt which consisted of mainly deletion, reversal and substitution strategies within his limited lexical and syntactic knowledge.

It is also likely that instructional practices had a contributory role in his approach to paraphrasing. The process of making only minor changes in lexis or syntax, resulting in a paraphrase that reflects the surface forms of the original, is typical of pedagogical practices (i.e. change grammatical forms; avoid copying directly from the original text and use synonyms). Note also despite Farid's repeated concerns about plagiarism, there was no author acknowledgement and extensive words were borrowed from the original text. Thus, it is highly likely that the missing citations in Farid's paraphrasing attempt not only highlight his inadequate understanding of paraphrasing, but also his unfamiliarity with academic writing conventions.

\section{Helen}

Helen was a final-year diploma student in the Faculty of Business and Design. She was Chinese and used mainly a local Chinese dialect and English as a means of communication. Helen reported she had consistently done well in English throughout her secondary schooling years (i.e., A1 in English for Malaysian Certificate of Education examination [SPM $]^{1}$ ). Unlike Farid, Helen was not required

\footnotetext{
${ }^{1}$ The Malaysian Certificate of Education examination (SPM) is undertaken at the end of upper secondary education.
} 
to take English support classes. Her proficiency was evident in the interview data in which she used English articulately. For the paraphrasing task, her SafeAssign report was $0 \%$. Based on Keck's (2006) taxonomy of paraphrase types, Helen's paraphrase falls into the "Moderate Revision" category.

\section{a) Acclimatising to paraphrasing}

Like Farid, Helen's first encounter with paraphrasing and plagiarism was in her very first semester in the university. In fact, Helen admitted that unlike summary writing she has never "heard about paraphrasing and plagiarism in school". Unlike secondary school, the importance of academic conventions was very evident in tertiary level. Helen explained, "I heard about it in every subject I took in my first year, in university. It was emphasised in all the subjects I took especially when we have assignments". According to Helen, as it was a new concept, she disclosed that "it was difficult at first". Despite her proficiency level, "understanding a sentence or paragraph and then writing it into our own sentence" still presents a daunting task for Helen. She explains that it was not enough "to just replace words" in the sentence. Her response reflects a higher understanding of what a paraphrasing task entails.

In the interview data, Helen reported that she still refers to the Harvard guide "to identify the source and to follow the example for in-text citation". She also discloses that she was gradually becoming more familiar with different types of academic sources. Helen explained, "The journals are still confusing me but the one's I'm familiar with are research article, web page and e-books". This act of acknowledging and integrating sources in writing was also reported as a new skill, one not covered in her previous educational institution.

Despite Helen's reported lack of experience with paraphrasing, she was very optimistic that she would be able to improve in the future. She stated, "I've only learnt this [paraphrasing] for more than a year. With practice, I think it will definitely improve". Like Farid, her motivation of improving her paraphrasing skills appears to originate from wanting to do well in her academic studies. As Helen put it, "although it's a new thing I learnt, it [paraphrasing] is a very important skill. At this level it's important to show that I am not copying and that I read a lot...use different sources other than BB [blackboard] notes".

\section{b) Retaining the original meaning}

Despite her proficiency level, Helen still expressed her concerns regarding paraphrasing. She reported that "understanding the paragraph was very hard for her". Unlike Farid, Helen spent the longest time (25 minutes) on Step 2, which was drafting and writing her paraphrase. Helen was able to identify all the main details and this was included in her paraphrase. Helen explained that this was the most crucial step in paraphrasing as she did not want to "understand the wrong thing and change the whole meaning intended by the author".

When asked whether the topic was familiar to her, Helen admitted that it was daunting at first since it was not covered in her business papers. Nonetheless, 
Helen explained that "the title of the article gave me some idea of what the passage would be about". She also explained that the second time reading the extract, she had a clearer idea of the extract and that the vocabulary was quite common. Helen explains, "Actually, I have seen them a lot in my other papers [points at 'global market', 'exponentially', 'components' and 'conventional']". As part of her paraphrasing process, Helen underlined the main ideas she identified in the extract. The underlining practice's purpose is twofold. Helen explains, "This [underlining] helps me in reading. I needed to do it many times for me to make sure I understand the meaning of the sentence". To her, the underlined words also take precedence in the paraphrasing task. "They [main ideas] must look different, but still mean the same". It is apparent that retaining the original meaning is imperative as part of the paraphrasing process for Helen. She sums it up succinctly, "It's not easy to put someone's ideas into my own words. Keeping the meaning the same is the biggest challenge".

\section{c) Processes of paraphrasing}

In comparison with Farid, it appears that the number of steps taken by Helen in order to produce the paraphrase was much lesser. This may be attributed to her proficiency level which greatly helped in her comprehension of the extract. Having a higher English proficiency level than Farid allowed her to achieve an indepth understanding of the ideas of the source author, identify key points of the text and produce her paraphrase. In other words, the reading to writing process became more efficient due to her strong command of the language. Helen displayed greater competency in paraphrasing as evidenced by both her SafeAssign report and the multiple paraphrasing techniques she reported in the interview. To illustrate, Helen restated the whole paragraph (i.e. replaces phrases and rearranges sentence structure) with few or no errors, and the original meaning is retained (see Table 5). Her paraphrase indicates knowledge of appropriate synonyms, as well as the forms and functions of dependent clause structures.

\section{Table 5}

Helen's Paraphrasing Attempt

\begin{tabular}{|c|c|}
\hline Original text & Helen's s attempt at Paraphrasing \\
\hline $\begin{array}{l}\text { Over the past two decades, the global } \\
\text { market of electrical and electronic } \\
\text { equipment (EEE) continues to grow } \\
\text { exponentially, while the lifespan of those } \\
\text { products becomes shorter and shorter. } \\
\text { Therefore, businesses as well as waste } \\
\text { management officials are facing a new } \\
\text { challenge, and e-Waste or waste } \\
\text { electrical and electronic equipment } \\
\text { (WEEE) is receiving considerable amount } \\
\text { of attention from policy makers. }\end{array}$ & $\begin{array}{l}\text { The growth of market of electrical and } \\
\text { electronic equipment (EEE) has } \\
\text { increased dramatically over the past ten } \\
\text { years due to the product's lifespan } \\
\text { which decrease. This problem has } \\
\text { attracted much attention from the } \\
\text { country leaders which turn out to be a } \\
\text { challenge for businesses and waste } \\
\text { management officials (Bhutta, Omar \& } \\
\text { Yang 2010). It is predicted that the } \\
\text { electrical devices will continue to raise in }\end{array}$ \\
\hline
\end{tabular}




\begin{tabular}{|c|c|}
\hline $\begin{array}{l}\text { Predictably, the number of electrical } \\
\text { devices will continue to increase on the } \\
\text { global scale. Consequently, the volume } \\
\text { of WEEE grows rapidly every year and is } \\
\text { also believed to be one of the most } \\
\text { critical waste disposal issues of the } \\
\text { twenty-first century. Compared to } \\
\text { conventional municipal wastes, certain } \\
\text { components of electronic products } \\
\text { contain toxic substances, which can } \\
\text { generate a threat to the environment as } \\
\text { well as to human health. }\end{array}$ & $\begin{array}{l}\text { number on a worldwide scale. As a } \\
\text { result, the amount of WEEE which } \\
\text { increases dramatically yearly is known to } \\
\text { be one of the most serious rubbish } \\
\text { dumping matters in the twenty first } \\
\text { century. Certain elements of electronic } \\
\text { products release unhealthy substance, } \\
\text { which can cause harm to the } \\
\text { surrounding as well as to people's heath } \\
\text { as compared to traditional; waste } \\
\text { management (Bhutta, Omar \& Yang } \\
\text { 2010). }\end{array}$ \\
\hline
\end{tabular}

*Note: Underlined words indicate similarity with original text

Some techniques included changing whole sentences instead of just one word with synonyms (i.e. continues to grow exponentially to has increased dramatically; and critical waste disposal issues to serious rubbish dumping matters), change in word class (i.e. grow to growth; and lifespan of product to product lifespan), change in sentence structure (i.e. This problem has attracted much attention from the country leaders, which turned out to be a challenge for businesses and waste management officials) and change of synonyms (i.e. element to components; environment to surroundings; and unhealthy to toxic). It is highly likely that all the above techniques appear automated and were readily available to Helen due to her English proficiency level.

Unlike Farid, Helen relied on the Harvard guide and seemed quite adept at identifying the relevant information for in-text citations. Interestingly, in her final step of paraphrasing Helen appeared to be very thorough as she revisited the draft and compared it to the original. Helen finished the paraphrase by adding one more citation at the end of her paraphrase. When asked why she added another citation, Helen stated that, "to be safe and also to clearly indicate the whole extract was written by the three authors". Note that both steps were lacking with Farid.

\section{Table 6}

Processes of paraphrasing

\begin{tabular}{cll}
\hline Step & Action & Purpose \\
\hline 1 & Read and underline & To understand the passage \\
& & To ensure main idea is included in \\
& & the paraphrase
\end{tabular}

2 Read and commence paraphrasing

(This is done sentence by

sentence)

Adding citation (used Harvard

To ensure the appropriate in-text

guide)

Changing of synonyms

Change of word class

Change or sentence structure 


\begin{tabular}{ll}
\hline Adding transitional words & \\
3 Read paraphrase & To make comparison with original \\
Review & To ensure that it is dissimilar in \\
& structure but retains the original \\
& meaning \\
\hline
\end{tabular}

\section{Discussion}

The findings of this study have revealed the complexity of paraphrasing for the novice $L 2$ writers. Interestingly, both Farid and Helen viewed paraphrasing as an invaluable skill which allows them to participate and do well in their respective disciplines. The importance of paraphrasing for the two students appears to originate from the goal of wanting to do well in their academic studies and also to avoid plagiarism. Both students viewing paraphrasing as a skill that benefits them in their studies highlight how these novice academic writers are not only acclimatising to the demands of academia, but also how they are able to develop a meaningful understanding of the value of paraphrasing. Nonetheless, paraphrasing was reported to be a demanding task for both students, for different reasons.

In this study, one of the many variables which contributed to the challenges faced when paraphrasing (for L2 writers) is L2 language proficiency. The data have indicated that the L2 proficiency level played a significant role in learner's' competency in various paraphrasing stages. For a learner who has lower L2 proficiency level, this meant that the challenge presented itself at the reading and comprehension level. To illustrate, insufficient lexical knowledge appears to be a major impediment for Farid. Note that he disclosed there were two main issues which impeded his paraphrasing; (i) difficulty in changing word class (i.e. adjective to noun); and (ii) creating grammatically correct sentences. Helen's higher proficiency level on the other hand, allowed her to use more relatively complex strategies in changing word forms and sentence structure. To illustrate, Helen was able to provide appropriate synonyms (i.e element (components), environment (surrounding) and unhealthy (toxic)) in her paraphrase. Farid, on the other hand, was unable to substitute the synonyms of keywords in the text (i.e. environment, substances, lifespan). In short, the L2 proficiency variable determines the paraphrasing strategies available to the students.

The $\mathrm{L} 2$ proficiency variable not only appears to affect Farid's overall confidence in paraphrasing, but also his understanding of the extract - causing him to lift heavily from the original source. Thus, it is imperative that students should be made aware that such strategies, coupled with no attribution of source could elicit accusations of plagiarism. The unfamiliar topic further complicated the paraphrasing task for Farid. This finding resonates that of Erhel and Jamet (2006), which affirmed that learners' ability to paraphrase correlates significantly with text comprehension. Farid's inferior paraphrasing skills reflects that of the low-proficiency learners from Johns and Mayes' (1990) study who tended to replicate sentences from the original text instead of paraphrasing. These data highlight the fact that students would benefit greatly from passage choice which is familiar to them. Sedhu, Lee and Choy (2013) advocates the selection of appropriate passages for paraphrasing instruction. 
This was founded based on their study where students performed better when the "passages are easy to comprehend, have obvious main points, have appropriate language level and have topics that are interesting...and relevant to students" ( $p$. 136).

Paraphrasing relies also heavily on interconnected sub-skills, that is, reading and writing skills. Wolfersberger (2013) clarifies that "the processes of reading and writing are individually very complex" (p. 51), and reading involves multiple processes such as "word recognition, orthographic processing, phonological processing, semantic and syntactic processing" (p. 50). Writing, on the other hand, involves multiple processes (Grabe \& Kaplan, 1996) which encompasses spelling, grammar and vocabulary, to name a few. Thus, it is highly likely that a competent paraphrase is only achievable when the student has the appropriate L2 language proficiency, reading and writing skills.

In this study, both students put great effort in order to understand the extract given to them. Both students incorporated strategies such as reading the extract multiple times, identifying the main ideas and also underlining the main ideas in the passage. This was followed by finding and considering appropriate lexical items. This was to ensure the original meaning of the author is retained. Helen, was successful in her paraphrasing as she displayed a higher order comprehension of the extract and reported a much more interdependent reading (inferring meaning through bottom-up and top down strategies i.e. "the title of the article gave me some idea of what the passage would be about") and writing processes (identifying familiar vocabulary i.e. "Actually, I have seen them a lot in my other papers"). However, for Farid; the student with lower L2 proficiency level, several main ideas were omitted and thus, the overall accuracy of the paraphrase was impacted. Evidently, crafting an accurate new paraphrase is cognitively demanding.

Another key point which emerged from the interviews was the fear of committing plagiarism. The perceived ideas about the paraphrasing function to avoid "copying" impacted the paraphrasing process. This raises another important issue - whether students, themselves have a clear understanding as to what constitutes an acceptable paraphrase. It is imperative that paraphrasing should be understood in a different light by the students. Hirvela and Du (2013) contend that paraphrasing should be seen more as a means of "meaningful opportunities for students to practice close reading of target texts and language and thus enhance their reading and writing skills" (p. 88). In fact, Yamada (2003) reports the many benefits of paraphrasing include the enhancement of inferential thinking and decision - making skills as they have to generate meaningful and accurate reconstructions of information.

The developmental perspective of viewing paraphrasing (i.e. Hirvela \& Du, 2013; Pecorari, 2003) provides room to grow for the novice L2 writer. In fact, Pecorari argues that "efforts to address it should start with the understanding that most students will use sources inappropriately before they learn how to use them appropriately" (p. 342). In this study, both students clearly require more instruction, guidance and practice to further improve their paraphrasing competency. Thus, their positive attitudes towards the importance of paraphrasing should be perceived 
as an opportunity for instructors (and course designers) to provide instructions that take into consideration their proficiency level, their area of disciplines and focus on academic vocabulary (Coxhead, 2012). Both students viewing paraphrasing as an invaluable skill and wanting to do well in their academic studies highlight opportunities to not only enhance their academic identity, but also academic legitimacy as students writers of $L 2$.

\section{Conclusion}

Previous research on the challenges that Malaysia L2 writers face when paraphrasing has provided somewhat a rather bleak picture. This study confirms that the issue is a complex one. The findings of this study suggest that students' linguistic competence impacts on their paraphrase strategy use. Accordingly, there is a need to view paraphrasing in a developmental perspective as such novice learners are bound to initially struggle as they acclimatize to the demands of academic writing. Furthermore, the links between writing skills in academic writing classes and learners' disciplines need to be more explicit not only in what paraphrasing can offer to them (i.e. reading-writing skills), but also metacognitive skills. The notion that skills are transferable may highlight the value of the skill, instead of its complexity. This can be done by focusing on academic vocabularies, sourcing materials which are familiar to students (i.e. those which are closely related to their respective disciplines) and making academic conventions such as citations, referencing, a familiar practice early on (i.e. pre-degree or matriculation programs). The findings also suggest that there is a need to utilise Content-Based Instruction to make the links between writing skills and learners' disciplines tangible. Research on reading-writing as an integrated skill is a relatively new field and much remains to be explored. This study, has illustrated that paraphrasing a text in L2 is certainly a complex cognitive endeavour and is influenced by multiple variables. Further research, perhaps involving more students with lower proficiency levels is needed to gain a better understanding of the phenomenon.

\section{References}

Abasi, A. R., \& Akbari, N. (2008). Are we encouraging patchwriting? Reconsidering the role of the pedagogical context in ESL student writers' transgressive intertextuality. English for Specific Purposes, 27(3), 267-284. doi: http://dx.doi.org/10.1016/j.esp.2008.02.001

Abasi, A. R., Akbari, N., \& Graves, B. (2006). Discourse appropriation, construction of identities, and the complex issue of plagiarism: ESL students writing in graduate school. Journal of Second Language Writing, 15(2), 102-117. doi: http://dx.doi.org/10.1016/j.jslw.2006.05.001

Abdullah, M. R., Abu Bakar, Z., Ali, R. M., Raja Yaacob, R. A. I., Rahman, A., Embong, A. M., \& Amar, A. Z. (2011). Writing strategies of Malaysian ESL undergraduate engineering learners. International Journal of Engineering and Technology, 11(2), 1-9. 
Anstrom, K., DiCerbo, P., Butler, F., Katz, A., Millet, J., \& Rivera, C. (2010). A review of the literature on academic English: Implications for K-12 English language learners. www.ceee.gwu.edu

Badiozaman, I. (2012). The relationship between Malaysian learner's self-concept and engagement in academic writing in one higher learning institution. Unpublished PhD dissertation, Massey University, New Zealand.

Barbour, R. S. (2008). Introducing qualitative research: $A$ student guide to the craft of doing qualitative research. London: Sage.

Barks, D., \& Watts, P. (2001). Textual borrowing strategies for graduate-level ESL writers. In D. Belcher \& A. Hirvela (Eds.), Linking literacies: Perspectives on L2 reading-writing connections (pp. 246-270). Ann Arbor, MI: The University of Michigan Press.

Berman, R., \& Cheng, L. (2010). English academic language skills: Perceived difficulties by undergraduate and graduate students, and their academic achievement. Canadian Journal of Applied Linguistics, 4(1-2), 25-40.

Blackboard Inc. (2010). Blackboard Learn Version 9.1. Safeassign Instructor Guide. Washington, DC: Blackboard Inc.

Bloch, J. (2009). Academic writing and plagiarism: A linguistic analysis English for Specific Purposes, 28(4), 282-285. doi: 10.1016/j.esp.2009.01.004

Bogdan, R. C., \& Biklen, S. K. (2007). Qualitative research for education: An introduction to theories and methods (5th ed.). Boston: Pearson International Edition.

Cohen, L., Manion, L., \& Morrison, K. (2007). Research methods in education (6th ed.). London: Routledge.

Coxhead, A. (2012). Academic vocabulary, writing and English for Academic Purposes: Perspectives from second language learners. RELC Journal, 43(1), 137-145. doi: $10.1177 / 0033688212439323$

Elton, L. (2010). Academic writing and tacit knowledge. Teaching in Higher Education, 15(2), 151-160.

Erhel, S., \& Jamet, E. (2006). Using pop-up windows to improve multimedia learning. Journal of Computer Assisted Learning, 22, 137-147.

Gebril, A., \& Plakans, L. (2013). Toward a transparent construct of reading-to-write tasks: The interface between discourse features an proficiency Language Assessment Quarterly, 10(1), 9-27.

Grabe, W., \& Kaplan, R. B. (1996). Theory and practice of writing. Harlow, England: Pearson Education.

Green, D. (2010). Words fail us: How academics view language and ideas in higher education research. International Journal for Academic Development, 15(1), 47-59.

Hirvela, A., \& Du, Q. (2013). "Why am I paraphrasing?": Undergraduate ESL writers' engagement with source-based academic writing and reading. Journal of English for Academic Purposes, 12(2), 87-98. doi: http://dx.doi.org/10.1016/j.jeap.2012.11.005

Howard, R. M. (1995). Plagiarisms, authorships, and the academic death penalty. College English, 57, 788-806. 
Janesick, V. (2000). The choreography of qualitative research design. In N. Denzin \& Y. Lincoln (Eds.), Handbook of Qualitative Research (2nd ed., pp. 379-399). Thousand Oaks: Sage.

Johns, A. M., \& Mayes, P. (1990). An analysis of summary protocols of university ESL students. Applied Lingustics, 11(3), 253-271.

Keck, C. (2006). The use of paraphrase in summary writing: A comparison of L1 and L2 writers. Journal of Second Language Writing, 15(4), 261-278. doi: http://dx.doi.org/10.1016/j.jslw.2006.09.006

Leki, I., Cumming, A., \& Silva, T. (2008). A synthesis of research on second language writing in English. New York: Routledge.

Lillis, T. M. (2001). Student writing: Access, regulation and desire. New York: Routledge.

Mutch, C. (2005). Doing educational research: A practitioners' guide to getting started. Wellington, NZ: NZCER Press.

Patton, M. (2002). Qualitative research and evaluation methods. Thousand Oaks, CA: Sage.

Pecorari, D. (2003). Good and original: Plagiarism and patchwriting in academic second-language writing. Journal of Second Language Writing, 12(4), 317345. doi: http://dx.doi.org/10.1016/j.jslw.2003.08.004

Puteh, S. N., Rahamat, R., \& Karim, A. A. (2010). Writing in the second language: Support and help needed by the low achievers. Procedia - Social and Behavioral Sciences, 7, 580-587. doi: 10.1016/j.sbspro.2010.10.078

Sedhu, D., Lee, M. Y., \& Choy, S. C. (2013). The influence of teaching strategies on students' paraphrasing strategies: A case study. International Journal of Independent Research and Studies, 2(3), 130-137.

Shafie, L. A., \& Nayan, S. (2011). The characteristics of struggling university readers and instructional approaches of academic reading in Malaysia. International Journal of Human Sciences, 8(1). http://www.insanbilimleri.com/en

Shi, L. (2004). Textual borrowing in second-language writing. Written Communication, 21(2), 171-200. doi: 10.1177/0741088303262846

Smith, M., Ghazali, N., \& Noor Minhad, S. F. (2007). Attitudes towards plagiarism among undergraduate accounting students: Malaysian evidence. Asian Review of Accounting, 15(2), 122-146.

Sun, Y. C. (2012). Does text readability matter? A study of paraphrasing and plagiarism in English as a foreign language writing context. Asia-Pacific Education Researcher, 21(2), 296-306.

Wette, R. (2010). Evaluating student learning in a university-level EAP unit on writing using sources. Journal of Second Language Writing, 19(3), 158-177. doi: 10.1016/j.jslw.2010.06.002

Wolfersberger, M. (2013). Refining the construct of classroom-based writing-from reading Assessment: The role of task representation. Language Assessment Quarterly, 10, 49-72.

Yigitoglu, N. (2010). Review of academic writing and plagiarism: A linguistic analysis. Journal of English for Academic Purposes, 9(3), 223-225. doi: 10.1016/j.jeap.2010.06.002 
Yu, G. (2008). Reading to summarise in English adn chinse: A tale of two languages. Language Testing, 25(4), 521-551.

Zhang, Y., \& Mi, Y. (2010). Another look at the language difficulties of international students. Journal of Studies in International Education, 14(4), 371-388. doi: $10.1177 / 1028315309336031$

Appendix A. Interview Guide

1. In your own words, what is paraphrasing?

2. Do you think paraphrasing is an important skill?

3. Do you incorporate paraphrasing skills in your studies? How?

4. What is easy about paraphrasing

5. What are some challenges in paraphrasing?

6. How would you describe your paraphrasing skills (5 Excellent 1 Poor)

7. Describe how you attempt a paraphrasing task.

8. What strategies do you incorporate when paraphrasing?

9. What are some of your concerns when paraphrasing?

10. Complete this sentence, "paraphrasing is easy / difficult because..." 
Appendix B Sample Paraphrase from Farid

\title{
SECTION B
}

Paraphrase the paragraph taken from a research article below. Don't forget to include an in-text citation.

Hindawi P:blisting Corporation

Economics Research International

Volume 20 , Article in $47 \div 230.8$ pages

doi: $10.1155 / 2011 / 474230$

\section{Research Article}

\section{Electronic Waste: A Growing Concern in Today's Environment}

\author{
M. Khurrum S. Bhutta, ${ }^{1}$ Ailnan Omar, ${ }^{2}$ and Xiaozhe Yang ${ }^{3}$

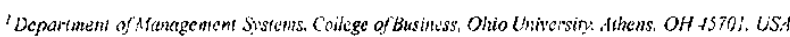

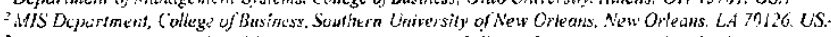

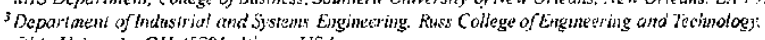 \\ Ohis University OH 4570 . Ativens. is. \\ Feccived 3 December 2010: Revised 18 March 2011: Accepted S April 2011
}

Over the past two decades, the global market of electrical and electronic equipment (EEE) continues to grow exponentially, while the lifespan of those products becomes shorter. Therefore, businesses as wcll as waste management officials are facing a new challenge, and $\mathrm{c}$-Waste or waste clcctrical and electronic equipment (WEEE) is receiving considerable amount of attention from policy maxers. Predictably, the number of electrical devices will continue to increase on the global scale. Consequently, the volume of WEEE grows rapidly every year and is also believed to be one of the most critical waste disposal issues of the twenty-first century. Compared to conventional municipal wastes, certain components of electronic products contain toxic substances, which can generate a threat to the environment as well as to human health.

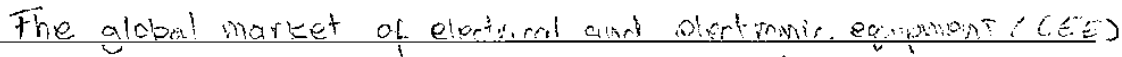

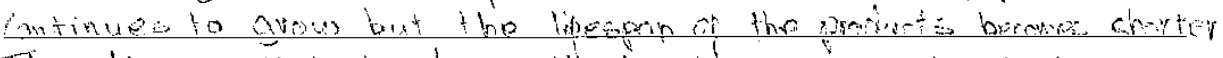
Thuse thes contribute to 2- Whato that roroved attenterns

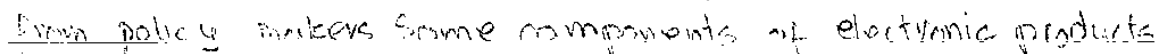

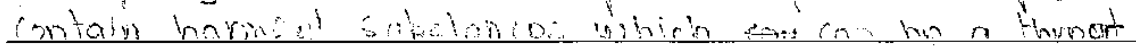
to tho onwermingt and to himan buling. 


\title{
Appendix C Sample Paraphrase from Helen
}

\section{SECTION B}

Paraphrase the paragraph taken from a research article below. Don't forget to include an in-text citation.

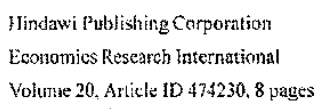

\section{Research Article}

\section{Electronic Waste: A Growing Concern in Today's Environment}

\author{
M. Khurrum S. Bhutta, ${ }^{1}$ Adnan Omar, ${ }^{2}$ and Xiaazhe Yang ${ }^{3}$

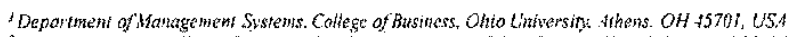

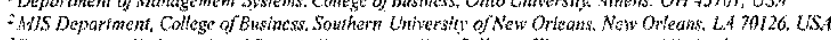 \\ ${ }^{3}$ Department of thdtustrial and Sirsems Enginetring. Russ College of Engineeritg and Techoolog: \\ Ohio Uhiversity OH $+5 \%$ I. Athens. USA \\ Recived 3 December 2010: Retised 18 March 201; Accepted 5 April 2011
}

Over the past two decades, the global market of electrical and electronic equipment (EEE) continues to grow exponentially, while the lifespan of those products becomes shorter. Therefore, businesses as well às waste management officials are facing a new challenge, and e-Waste or waste electrical and electronic equipment (WEEE) is receiving considerable amount of attention from policy makers. Predictably, the number of electrical devices will continue to increase on the global scale. Consequently, the volume of WEEE grows rapidly every year and is also believed to be one of the most critical waste disposal issues of the twenty-first century. Compared to conventional municipal wastes, certain components of electronic products contain toxic substances, which can generate a threat to the environment as well as to human health.

The growth of market of electrical and electronic equipment (EEE) has increased dramaticauly over the past ten years due to the products' lifespan which decrease. This problem has attracted much attention from the country leaders which turn out to be a challenge for businesses and waste management officiods (Bhutta, Dmar \& Yang 2010) -As a result, the It is predicted that the electrical devices will continue to raise in number on a worldwide scale. As a result, the amount of WEEE which increase dramatically yearly and is known to be one of the

most serious rubbish dumping matters in the twenty-first century. Certain elements of electraic products untealthy substarice, which can cause harm to the surrinding as well as to people's health as compared to the traditional waste management (Bhutta. Omar \& Yang 2010). 